\title{
A FORMAÇÃO DO LICENCIANDO EM MÚSICA NA PERSPECTIVA DA DIVERSIDADE CULTURAL
}

\author{
Andeson Cleomar dos Santos $\underset{1}{-}$; Simone Marques Braga $\stackrel{2}{2}$ \\ 1. Bolsista PIBIC/CNPq, Graduando em Licenciatura em Música, Universidade Estadual de Feira de Santana, e-mail: \\ andesoncleomar@gmail.com \\ 2. Orientadora Simone Marques Braga, Departamento de Letras e Artes, Universidade Estadual de Feira de Santana, \\ e-mail: moninhabraga@gmail.com
}

PALAVRAS-CHAVE: Diversidade Cultural, Formação Docente, Legislação.

\section{INTRODUÇÃO}

Esta investigação teve por objetivo pesquisar de que forma a diversidade cultural está sendo abordada na formação inicial dos estudantes do Curso de Licenciatura em Música da Universidade Estadual de Feira de Santana (UEFS) e também se a mesma faz parte das práticas pedagógicas iniciais dos licenciandos, enquanto bolsistas nas escolas assistidas pelo Programa Institucional de Bolsa de Iniciação à Docência (PIBID). A investigação se apoiou em alguns autores, leis e documentos a exemplo de Penna (2014), Santiago e Ivenicki (2016), Borges (2010), DaMatta, (1981), Laraia (2001), Rocha (1988), Lei n 11.645/08, Parecer CNE/CP 03 e Resolução CNE/CP 01/2004, entendendo a importância de se contemplar as culturas e histórias de matrizes africanas, afro-brasileiras e indígenas na formação inicial e atuação posterior na educação básica. Trata-se de uma pesquisa qualiquantitativa, que teve como instrumentos de coleta a aplicação de questionários, a análise da matriz curricular e de atividades acadêmicas do curso de Licenciatura em Música da UEFS.

\section{METODOLOGIA}

Trata-se de uma pesquisa qualiquantitativa, visto que foram coletados tanto dados quantitativos, quanto dados qualitativos. No sentido quantitativo, foi feita a verificação do percentual dos componentes curriculares relacionados com a temática diversidade cultural na matriz curricular do curso de Licenciatura em Música da UEFS. Qualitativamente, foi feito um levantamento analítico das ementas e atividades desenvolvidas no curso de Licenciatura em Música da UEFS. Como instrumentos de coleta de dados foi realizada pesquisa documental acerca da matriz curricular e análise das atividades do curso que contemplavam questões de diversidade cultural.

Foi feito um levantamento de documentos e registros existentes referentes às disciplinas da matriz curricular, bem como das atividades desenvolvidas pelo curso de Licenciatura em Música que contemplam a diversidade cultural. Além desses documentos foram verificados documentos do "Programa de Política de Acesso, Permanência e Pós Permanência" da UEFS, com o objetivo de verificar as ações desenvolvidas pelo programa e seus reflexos na formação docente na perspectiva da diversidade cultural, no âmbito da UEFS.

Vale ressaltar, que a pesquisa teve como ponto de partida a investigação realizada na investigação intitulada "As relações étnicas e culturais nas escolas feirenses no âmbito das práticas pedagógicas musicais", realizada nos anos de 2015, que teve como objeto de investigação a atuação inicial dos estudantes junto ao PIBID, para verificar se a 
diversidade cultural era contemplada na atuação inicial dos estudantes do curso. Assim, foi pensado em desenvolver essa pesquisa junto a formação desses estudantes para verificar se a atuação reflete a formação desenvolvida.

Após a coleta e análise da investigação anterior, foi constatado que as culturas indígenas não foram referenciadas na atuação dos bolsistas do PIBID, por falta de conhecimento dos mesmos acerca dessas culturas. Logo, com o objetivo de possibilitar esse conhecimento e contribuir com a valorização das culturas indígenas na formação inicial de professores da UEFS, como parte desta pesquisa, foram desenvolvidas oficinas ministradas pelo pesquisador, através da socialização de vivências musicais do povo Pankararu.

\section{ANÁLISE}

Sobre a matriz curricular, das 2.800 horas, 790 horas equivalem a 14 componentes ofertados em caráter obrigatório, aos quais alguns se relacionam e contemplam com a diversidade cultural. Estes 14 componentes perfazem o equivalente a 28,21\% das disciplinas do LICEMUS. No primeiro semestre, foram identificados dois componentes curriculares que se relacionam à temática: 1) Introdução à Antropologia (CHF 301), com carga horária de 60 horas; 2) Relações Étnico-Raciais na Escola (EDU 311), 60 horas. Ambos os componentes são ofertados pelo Departamento de Educação. No segundo semestre, também foram identificadas duas disciplinas: História Geral da Arte (LET502), com a carga horária de 60 horas; Elementos de Etnomusicologia (LET644), com uma carga horária menor, com 30 horas. No sexto e sétimo semestres, localiza-se uma disciplina: História e Diversidade da Música Brasileira I (LET692), com 45 horas. A disciplina é pré-requisito para que o estudante possa matricular nos componentes História e Diversidade da Música Brasileira II (LET693), de 45 horas, ofertada no sétimo semestre.

Em seguida foram localizadas os componentes optativos, sendo identificadas três disciplinas: Mitologia e práticas musicais afro-descendentes (LET 675), com a carga horária de 60 horas; Mitologia e práticas musicais dos indígenas brasileiros (LET 676), carga horária de 60 horas; 9) Canto popular Instrumental e vocal (LET 643), com 60 horas. É importante ressaltar que há outras disciplinas que se enquadram nessa perspectiva como Música e Interface, Composições de Microcações, Improvisação e Criação, Prática Orquestral e Música Baiana (esta última que será ofertada em 2017.02). No entanto elas são disponibilizadas com o codinome de "Tópicos Especiais de Estudo em Música - I, II, III e IV'.

Em relação às disciplinas eletivas, foram identificadas duas disciplinas: Formação de Contadores de Histórias (EDU 925), com a carga horária de 60 horas; e História da Arte Baiana (LET 976), também com 60 horas.

Um dado significante nesta análise foi percebido a partir da experiência do pesquisador enquanto estudante do curso, ao vivenciar e certificar com seus colegas que na matriz curricular do curso, além dos componentes identificados, é oportunizado espaços, em outros componentes, para que a diversidade cultural seja contemplada. Este espaço depende da escolha do estudante, se tiver interesse na temática poderá desenvolver ações, a exemplo de pesquisa, proposta pedagógica ou investigar propostas pedagógicas desenvolvidas em algumas etnias, associados aos seguintes componentes curriculares: 1) Estágio Supervisionado II (LET 687); 2) Estágio supervisionado III (LET 688); Estágio supervisionado IV (LET 689); 4) Pesquisa I (LET 679); 5) Pesquisa em músical II (LET 680); 6) Pesquisa em músical III (LET 681); 7) Pedagogia do Instrumento (LET 651).

Sobre as atividades envolvendo a diversidade, foram identificadas 13 e ocorreram nos 
anos de 2013, 2014, 2016 e 2017. Dessas 13, 07 eram atividades de ensino, 02 de extensão e 04 envolvendo ensino e extensão. Razão pela qual, a maioria das atividades se referem a apresentações musicais promovidas por disciplinas, envolvendo estudantes do curso. Os objetivos das atividades eram na sua maioria promover práticas musicais discentes, ao contemplar gêneros diversos, proporcionar aos alunos envolvidos a experiência da performance, o contato com o público, ampliar repertório, conhecer e respeitar a diversidade musical e fornecer subsídios para desenvolvimento de habilidades de gestão/organização de apresentações. Apesar do repertório ser variado e auxiliar na aproximação dos licenciandos com a diversidade cultural, há uma maior inclinação para músicas provenientes da cultura afro-brasileira e midiática. Por fim, ao analisar documentos do Programa de Política de Acesso, Permanência e Pós Permanência, nota-se que às ações da UEFS em busca de possibilitar o acesso de diversas comunidades, ao favorecer uma universidade pautada na diversidade.

\section{CONSIDERAÇÕES FINAIS}

Da análise da formação dos estudantes, nas atividades desenvolvidas pelo curso, em sua grande maioria de caráter prático-musical, há uma valorização da diversidade cultural brasileira que, consequentemente ajuda a aproximar os licenciandos a essas questões. Todavia, apesar das temáticas envolvidas serem variadas, assim como na atuação inicial, nota-se uma maior abordagem nas culturas afro-brasileiras e midiáticas, enquanto às culturas indígenas são apresentadas sem tanta profundidade.

Isso pode acontecer pelo desconhecimento sobre esses povos e a escassez de materiais didáticos e produções acadêmicas de forma geral. Esse dado reforça as considerações dos autores Santiago e Ivenicki (2016) sobre a escassez de produções científicas e poucas ofertas de disciplinas na matriz curricular de Licenciaturas em Música que contemplem culturas indígenas.

Sem dúvida, que as práticas musicais desenvolvidas durante a graduação contribuem para uma atuação posterior contextualizada e mais eficaz nos sentido musical e social da diversidade cultural. Assim, como subsídios para lidar com a diversidade cultural presente na sala de aula, em um caráter mais prático, em que algumas disciplinas ajudam a lidar com desafios que essas questões trazem ao educador. Entretanto, a formação não diz respeito apenas às práticas musicais desenvolvidas, mas traduz uma proposta que deve ser refletida na matriz curricular do curso.

Assim, sobre a matriz curricular, 28,21\% das disciplinas obrigatórias do LICEMUS, contemplam a diversidade cultural contribuindo significativamente para a formação dos futuros professores, no sentido de evocar a consideração da diversidade e das relações entre etnias variadas. Todavia, apesar de uma carga horária pequena, ao analisar o total de horas dos componentes de caráter obrigatório, contribuem mais em uma perspectiva teórica, com discussões, leitura de textos, documentos e legislações que asseguram a abordagem de diferentes etnias, com o foco em questões teóricas e não prático-musicais. As práticas musicais envolvendo a diversidade são mais desenvolvidas em disciplinas de caráter optativo ou eletivo, que depende da escolha do discente de cursar ou não.

Dentre o percentual restante das disciplinas obrigatórias, ou seja, 71,79\%, algumas favorecem o desenvolvimento de conhecimento da cultura europeia ocidental, pois, são componentes que tem um foco na escrita musical ocidental, como também em seus conceitos musicais, padrão de compor, executar e escutar essas músicas, desenvolvidas a partir da concepção da cultura erudita européia.

Sobre os professores que ministram as disciplinas obrigatórias que contemplam a diversidade, destaca-se o fato de que grande parte serem conduzidas por profissionais contratados em caráter temporário. Assim, tão importante quanto a carga horária ou a 
sua proporção dentro do total de horas do curso, é a responsabilidade das instituições de ensino superior de desconstruir visões errôneas sobre algumas culturas, etnias, para desfazer uma visão estereotipada, preconceituosa e discriminatória. Diante disso, as instituições devem não só ficar atentos nas contratações dos profissionais que atuarão nessa área, mas também ampliar concursos para profissionais que lidem com essas questões como docentes indigenistas e/ou indígenas por exemplos, na busca por uma política afirmativa nas instituições, ao trazer suas realidades de lutas, assim como docentes negros e quilombolas que lidem diariamente com essas temáticas em seu cotidiano.

Contudo, pelo conjunto dos dados coletados, o curso de Licenciatura em Música da UEFS mostra-se preocupado com a formação de seus licenciandos na perspectiva da diversidade cultural. Assim, apesar das considerações levantadas, a diversidade cultural está presente na formação e atuação inicial dos estudantes e bolsistas do PIBID-Música da UEFS. No entanto, não acontecesse de forma equilibrada, ao considerarmos o equilíbrio entre saberes, culturas e conhecimentos desenvolvidos no curso, principalmente os relacionados a cultura ocidental européia, diante das necessidades de desenvolver uma educação igualitária culturalmente.

\section{REFERÊNCIAS}

BORGES, Elisabeth Maria de Fátima. A Inclusão da História e da Cultura Afro brasileira e Indígena nos Currículos da Educação Básica. In Revista. Mest. Hist., Vassoura, v. 12, n. 1, p. 71-84,jan/jun., 2010.

CONSELHO NACIONAL DE EDUCAÇÃO RESOLUÇÃO No ${ }^{\circ}$. Diretrizes Curriculares Nacionais para a Educação das Relações Étnico Raciais e para o Ensino de História e Cultura Afro-Brasileira e Africana. 17 de julho de 2004. (*)

DAMATTA, Roberto. VOCÊ TEM CULTURA?. Suplemento Cultural/ Jornal da Embratel. Setembro de 1981.

LARAIA, Roque de Barros. Cultura um conceito Antropológico. 14 ${ }^{\mathrm{a}}$ edição. 2001. Editor Ltda. Rio de Janeiro. ISBN 85-7110-438-7. PASSOS, Joana Célia. As Relações Étnico-Raciais nas Licenciaturas: O que dizem os currículos anunciados In: POIÉSIS Revista do Programa de Pós-Graduação em Educação - Mestrado, n 3., Universidades do Sul de Santa Catarina, 2014.

PENNA, Maura. Poéticas Musicais e práticas Sociais: reflexões sobre a educação musical diante da diversidade. In: A música (s) e seu Ensino. $2^{\circ}$ ed.rev. e ampl. Porto Alegre: Editora Sulina 2014.

ROCHA, Everardo P. Guimarães. "O que é Etnocentrismo". pág. 7-22). ISBN: 85-11-01124-2 . $1^{\text {a }}$ edição 1984. $5^{\text {a }}$ edição Editora brasiliense 1988

SANTIAGO, Renan (UFRJ) e IVENICKI Ana (UFRJ). Multiculturalismo na formação de professores de música: o caso de três instituições de ensino superior da cidade do Rio de Janeiro. OPUS - Revista Eletrônica da Associação Nacional de Pesquisa e Pós-graduação em Música (스PPOM) ISSN 0103-7412 (versão impressa, 1989-2008), ISSN 1517-7017 (versão online, 2009- ) 